\title{
DOES THE LAW OF ONE PRICE (LOP) HOLDS IN THE INTERNATIONAL BARLEY MARKETS
}

\author{
Sadiq, M.S ${ }^{1}$., Singh, I.P ${ }^{2}$, Ahmad, M.M ${ }^{3}$. \\ ${ }^{1}$ Department of Agricultural Economics and Extension, FUD, Dutse, Nigeria \\ ${ }^{2}$ Department of Agricultural Economics, SKRAU, Bikaner, India \\ ${ }^{3}$ Department of Agricultural Economics, BUK, Kano, Nigeria \\ *corresponding author: sadiqsanusi30@ gmail.com (+2347037690123)
}

\begin{abstract}
A price time-series data of barley for a period of 49 years (1970-2019) sourced from the FAO database was used to determine the horizontal market integration of barley among some selected major market players in barley trade in the world. The chosen markets are Australia, Canada, Iran, Turkey and the USA based on the availability of up-to-date large span data. The collected data were analyzed using inferential statistics- unit root tests, co-integration tests, unrestricted vector autoregressive model, Granger causality test and impulse response function. The empirical evidence showed that the law of one price (LOP) exists among the selected markets i.e. there is perfect price communication among the markets in the long run, thus highly integrated. Besides, Australian and Canadian markets established a long-run equilibrium, thus have a stable price in the long run. Furthermore, the import and export hubs of barley in the trade are Canadian, USA and Turkey markets while Iranian and Australian markets are large consumer markets. The empirical evidence showed Canadian and USA markets to be the major players in the trade while the Australian market is a follower in the trade. All the selected markets have promising future prices with a little inflationary trend which will owe to supply fluctuation. The reinforcement of physical infrastructure, the use of ICTs and well-defined consistent agricultural policy/market initiatives would thus lead to the global creation of a single uniform economic market for barley.
\end{abstract}

Keywords: Barley, international, markets, LOP, spatial

http://dx.doi.org/10.21776/ub.agrise.2021.021.4.1

Received 2 March 2021

Accepted 10 October 2021

Available online 31 October 2021

\section{INTRODUCTION}

In recent years, market integration research has gained a lot of attention (Sanogo and Amadou, 2010) as it has become a core topic in many current debates on the issues of market liberalization (Mukhtar and Javeed, 2008). Market integration is most usefully defined as tradability or contestability between markets, according to Barrett and Li (2002); Barrett (2008). This concept involves the mechanism of market clearance (spatial equilibrium) in which prices and trade flows are collectively decided by demand, supply and transaction costs in different markets, as well as the transition of price shocks from one market to another, or both. The notion of tradability is characterized by Barrett (2008) as the fact that a good is traded between two economies or those market intermediaries are indifferent between, and do not export from one market to another. Tradability signals, as captured in actual or potential physical flows, the movement of surplus demands from one market to another. Under the tradability criterion, positive trade flows are adequate to show spatial market integration, though prices may not equilibrate across markets. The conceptualization of spatial market integration as tradability is only compatible with market efficiency when prices equilibrate across markets while trade occurs.

Utilities of form, time and place control output, consumption and help make successful marketing decisions as well. These decisions are driven by price signals that decide the flow of marketing activities and provide guidance on the disposal of supplies (Wani et al., 2015). A requirement for a sound marketing system is the efficient operation of markets. It provides the farmers-sellers with 
remunerative commodity prices as well as countless customers with products at fair prices (Singh, 2014). The presence of a high degree of integration in those markets is one of the common measures of the efficient functioning of markets. The nature of market integration affects the conduct of the firms in the markets and thus the efficacy of the marketing. A highly integrated market's behaviour varies from that of a disintegrated market (Singh, 2014). Nonintegrated markets provide an incorrect picture of price information that can distort producers' production decisions and contribute to inefficiencies in agricultural markets, harm ultimate customers and lead to low production and slow development (Mukhtar and Javed, 2008; Ahmed and Singla, 2017).

Traditionally, the transmission of international commodity prices has been examined in the context of the theoretical framework of the law of one price (LOP), which states that trading markets tend to show equivalent prices for equal goods at a rate measured by the effectiveness of transmission (Larre, 2019). However, as advances related to co-integration research came along, the LOP came under extreme scrutiny since several studies found no supportive evidence for it. It was initially checked for by linear correlations. According to Listorti and Esposti (2012); Larre (2019), academic literature has taken the existence of co-integration as ample evidence of market integration since the influential work of Ardeni (1989). This is because both the validity of the LOP and the existence of co-integration are necessary for a stable (non-stationary) long-run relationship (Ardeni, 1989; Larre, 2019).

Information on spatial market integration will provide insights into a competition, arbitration efficiency and pricing efficiency, thus helping to understand the overall performance of the market. Market integration studies can dispense with the details of market performance needed for policy formulation and macroeconomic modelling. Price signals transmitted by non-integrated markets will also mislead the marketing decisions of producers and result in inefficient movement of goods. In addition, it is often difficult to understand trade policy, as a variety of barriers, such as stocking quotas, inefficient markets, poor supply chains and trade cartels, frequently limit the successful functioning of markets (Chengappa et al.,2012; Ahmed and Singla, 2017).

What will bring full benefits to all the players in the marketing chain is a well-coordinated and effective marketing system (Praveen and Inbasekar, 2015). The competitiveness of the markets is demonstrated by the high degree of market integration. A well-integrated market gives farmers the means to specialize on a competitive advantage basis (Ahmed and Singla, 2017). The high degree of market integration means that the markets are very competitive and provide little basis for substantial and expensive government intervention aimed at increasing competition to increase market performance (Mukhtar and Javed, 2008; Sadiq et al., 2020).

Thus, the prerequisites for an effective marketing system are perfect market integration and full price transmission (Sadiq et al., 2018). A marketing system of this standard will omit non-profit arbitrage and alter the price adjustments easily (Sadiq et al., 2016; 2020). The study of the price movement of goods in the corresponding and associated markets helps to determine the efficacy of the worldwide marketing mechanism for the selected crop. The ultimate aim of agricultural marketing planners and policymakers is to establish productive markets for agricultural products produced in the region/globe by farmers. Farmers can get the remunerative price of the commodity they produce and can be motivated to increase production at a tempo.

Given the importance of the information emerging from market integration studies, an attempt is made here to discern the status of market integration between the world's international barley markets. This study would help to explain the effectiveness of price policy because if all the major barley markets were not integrated at the international level, international price policy would not be acceptable. Besides, to the best of our knowledge, literature shows little or no empirical evidence on the international market integration of barley despite its economic and political tempo in global trade.

Instead of the foregoing, the present research determined the horizontal market integration of barley in the world. The specific objectives focused on the extent of market integration among the selected markets; the degree of market integration among the selected markets; the process of price formation in these markets; the effect of innovations-shocks on these markets; and, the future prices of barley in the international market.

\section{RESEARCH METHODOLOGY}

Time series data of 49 years (1970-2019) that covered barley producer prices of Australia, Canada, Iran, Turkey and USA; sourced from FAO data bank were used for the study. The selected markets were chosen based on the availability of large data that spanned over a long period to allow for efficient analysis. The collected data were analyzed using inferential statistics. Objectives I, III and IV was achieved using co-integration tests (Engle and Granger co-integration; and, Johansen maximum likelihood co-integration tests); Granger causality test; and, impulse response function respectively; while 
vector error correction model (VECM) was used to achieve both objectives II and V.

\section{Model Specification}

\section{Lag Selection Criteria}

The information criteria are computed for the VAR models of the form:

$Y_{t}=A_{1} Y_{t-1}+\ldots \ldots .+A_{n} Y_{t-n}+B_{q} X_{t-q}+C D_{t}+\varepsilon_{t}$

Where $Y_{t}$ is $K$-dimensional. The lag order of the exogenous variables $X_{t}, q$, and deterministic term $D_{t}$ have to be pre-specified. For a range of lag orders $n$ the model is estimated by OLS (Sadiq et al., 2016). The optimal lag is chosen by minimizing one of the following information criteria:

$$
\begin{aligned}
& A I C(n)=\log \operatorname{det}\left\{\sum_{u}(n)\right\}+\left(\frac{2}{T}\right) n K^{2} \ldots \ldots \ldots . \\
& H Q(n)=\log \operatorname{det}\left\{\sum_{u}(n)\right\}+\left(\frac{2 \log \log T}{T}\right) n K^{2} \ldots \\
& S C(n)=\log \operatorname{det}\left\{\sum_{u}(n)\right\}+\left(\frac{\log T}{T}\right) n K^{2} \ldots \ldots . \\
& F P E(n)=\left(\frac{T+n^{*}}{T-n^{*}}\right)^{k} \operatorname{det}\left\{\sum_{u}(n)\right\} \ldots \ldots \ldots \ldots \ldots
\end{aligned}
$$

Where $\sum_{u}(n)$ is estimated by $T^{-1} \sum_{t=1}^{T} U_{t} U_{t}^{1}, n^{*}$ is the total number of parameters in each equation of the model when $n$ is the lag order of the endogenous variables, also counting the deterministic terms and exogenous variables. The sample length is the same for all different lag lengths and is determined by the maximum lag order (Sadiq et al., 2016).

\section{Augmented Dickey-Fuller test}

Following Sadiq et al. (2017) the autoregressive formulation of the ADF test with a trend term is given below:

$\Delta P_{t}=\alpha+P_{t-1}+\sum_{j=2}^{i t} \beta_{i} \Delta P_{i t-j+t}+\varepsilon$

Where, $P_{i t}$ is the price in the market $i$ at the time $t, \alpha$ and $\Delta P_{i t}\left(P_{i t}-P_{t-1}\right)$ is the intercept or trend term.

\section{Engel and Granger co-integration test}

Following Engle and Granger (1987), the formulation tests on residual from the co-integration test are given below:

$$
P_{1}=\alpha+P_{2}+\varepsilon
$$

Where

$P_{1}$ and $P_{2}$ are two price series from different markets ,$\alpha$ is constant, and $\varepsilon$ is noise

The residuals from the above equation are considered to be temporary deviations from the long-run equilibrium. ADF unit root test is then conducted on the residual obtained from equation (7)

\section{Johansen's co-integration test}

Following Johansen (1988); Sadiq et al.(2018) the multivariate formulation is specified below:

$P_{t}=A_{1} P_{t-1}+\varepsilon_{t}$

So that

$\Delta P_{t}=A_{1} P_{t-1}-P_{t-1}+\varepsilon_{t}$

$P_{t}=\left(A_{1}-1\right) P_{t-1}+\varepsilon_{t}$

$\Delta P_{t}=\prod P_{t-1}+\varepsilon_{t}$
Where, $P_{t}$ and $\varepsilon_{t}$ are $(n \times 1)$ vectors; $A_{t}$ is an $(n \times n)$ matrix of parameters; $I$ is an $(n \times n)$ identity matrix, and $\prod$ is the $\left(A_{1}-1\right)$ matrix.

Using the estimates of the characteristic roots, the tests for the number of characteristic roots that are insignificantly different from unity were conducted using the following statistics:

$\lambda_{\text {trace }}=-T \sum_{i=r+1}^{n} \ln \left(1-\lambda_{i}\right)$

$\lambda_{\text {max }}=-T \ln \left(1-\lambda_{i}+1\right)$

Where, $\lambda_{i}$ denotes the estimated values of the characteristic roots (Eigen-values) obtained from the estimated $\Pi$ matrix, and $T$ is the number of usable observations.

\section{Granger causality test}

Following Granger (1969); Sadiq et al.(2017) the model used to check whether market $P_{1}$ Granger causes market $P_{2}$ or vice-versa is given below:

$P_{t}=\alpha+\sum_{i=1}^{n}\left(\varnothing P_{1 t-i}+\delta_{i} P_{2 t-i}\right)+\varepsilon_{i}$

A simple test of the joint significance of $\delta_{i}$ was used to check the Granger causality i.e.

$H_{0}:=\delta_{1}=\delta_{2}=\ldots \ldots . . \delta_{n}=0$.

\section{Vector error correction model (VECM)}

The VECM explains the difference in $y_{t}$ and $y_{t-1}$ (i.e. $\Delta y_{t}$ ) and it is shown below (Sadiq et al., 2016; Sadiq et al., 2020):

$\Delta \gamma_{t}=\alpha+\mu\left(\gamma_{t-1}-\beta_{x t-1}\right)+\sum_{i=0}^{i=t} \delta_{i} \Delta x_{t-1}+$

$\sum_{i=1}^{i=t} \gamma_{i} \Delta \gamma_{t-1}$

It includes the lagged differences in both $x$ and $y$, which have a more immediate impact on the value of $\Delta \gamma_{t}$.

\section{Impulse response functions}

The generalized impulse response function (GIRF) in the case of an arbitrary current shock $(\delta)$ and history $\left(\omega_{t-1}\right)$ is specified below (Rahman and Shahbaz, 2013; Beag and Singla, 2014) :

$\operatorname{GIRF}_{Y}\left(h, \delta, \omega_{t-1}\right)=E\left[Y_{t}+h \mid \delta, \omega_{t-1}\right]-$ $E\left[Y_{t-1} \mid \omega_{t-1}\right]$

\section{Forecasting accuracy}

Mean absolute prediction error (MAPE), relative mean square prediction error (RMSPE), relative mean absolute prediction error (RMAPE), Theil's U statistic, and $\mathrm{R}^{2}$ were determined using the following formulas to test accuracy in the fitted time series model:

$M A P E=1 / T \sum_{i=1}^{5}\left(A_{t-1}-F_{t-1}\right)$

RMPSE $=$

$1 / T \sum_{i=1}^{5}\left(A_{t-1}-F_{t-1}\right)^{2} / A_{t-1}$

$R M A P E=1 / T \sum_{i=1}^{5}\left(A_{t-1}-F_{t-1}\right) / A_{t-1} \times 100$

$\begin{aligned} U & =\sqrt{\frac{\sum_{t=1}^{n-1} \frac{\left(\widehat{Y}_{t+1}-Y_{t+1}\right)^{2}}{Y_{t}}}{\sum_{t=1}^{n-1} \frac{\left(Y_{t+1}-Y_{t}\right)^{2}}{Y_{t}}}} \\ R^{2} & =1-\frac{\sum_{i=1}^{n}\left(A_{t i}-F_{t i}\right)}{\sum_{i=1}^{n}\left(A_{t i}\right)}\end{aligned}$ 
Where, $R^{2}=$ coefficient of multiple determination, $A_{t}$ $=$ Actual value; $F_{t}=$ Future value, and $\mathrm{T}=$ time period

\section{RESULTS AND DISCUSSION Lag Selection Criteria}

Too many lags could increase the forecast error; too few could leave out the pertinent information (Sadiq et al., 2018). The best way to determine the number of lags required is usually through experience, expertise and theory (Sadiq et al., 2018). To choose the optimal truncation lag length to ensure that the errors are white noise in ADF, the Akaike Information Criterion (AIC), Schwarz Bayesian Information Criterion (BIC) and Hannan-
Quinn Criterion (HQC) were used. The lag selection criteria for the logarithm transformed prices viz. Schwarz Bayesian criteria (SBC) and Hannan-Quinn criterion (HQC) recommended the selection of lag one (1) while the Akaike information criterion (AIC) advised that lag six (6) should be chosen (Table 1). To have parsimonious results and avoid biases of time series due to their sensitive nature towards lag length, the democratic principle was applied (Sadiq et al., 2017), thus lag one (1) was chosen as the appropriate length for the truncation.

Table 1: Lag selection criteria

\begin{tabular}{|c|r|r|r|}
\hline Lag(s) & \multicolumn{1}{|c|}{ AIC } & \multicolumn{1}{c|}{ BIC } & \multicolumn{1}{c|}{ HQC } \\
\hline 1 & -1.357679 & $0.061563^{*}$ & $-0.831355^{*}$ \\
\hline 2 & -0.841638 & 1.591347 & 0.060630 \\
\hline 3 & -1.199171 & 2.247559 & 0.079043 \\
\hline 4 & -1.183507 & 3.276967 & 0.470652 \\
\hline 5 & -0.866298 & 4.607920 & 1.163806 \\
\hline 6 & $-2.034662 *$ & 4.453300 & 0.371387 \\
\hline
\end{tabular}

Source: Computer printout, 2021

Note: $*$ denote lag length selected by a criterion

\section{Unit Root Tests}

The ADF unit root test of the transformed logarithm price series showed that at level, the market prices of Australian and USA barley were nonstationary while that of Canada, Iran and Turkey attained stationary as evidenced by their respective tau-statistics which were not different from zero at 5\% degree of freedom for the former and different from zero at $5 \%$ probability level for the latter (Table 2 ). Thereafter, at the first difference, the trend laded price series-white noise: Australian and USA barley became stationary as indicated by their respective tau-statistics which were different from zero at $5 \%$ probability level. Furthermore, the KPSS test for the unit root rejected the null hypothesis of stationary at a level for prices series viz. Australian, Canadian, Turkey and USA as indicated by their respective absolute taustatistics which were greater than the t-critical value at $5 \%$ significance level. However, at level, it failed to reject the non-stationary hypothesis for the market price series of Iranian barley as evidenced by its absolute tau-statistic value which is lower than the $\mathrm{t}$ critical value at $5 \%$ significance level. But at the first difference, the price series-Australian, Canadian and USA markets became stationary as indicated by their respective t-statistics in absolute terms which were less than the t-critical value at $5 \%$ significance level. Besides, the price series of Turkey failed to attain stationarity at first difference until when it was differenced twice (second difference) as indicated by its respective tau-statistics which were not different from zero and different from zero at $5 \%$ significance level for the former and latter respectively. Generally, it can be inferred that the price series were integrated of different order i.e. $\mathrm{I}(0)$ and $\mathrm{I}(1)$, thus suggesting the application of bound test/Autoregressive distributed lag (ARDL) model. Due to the inherent weakness of these conventional unit root test models- ADF and KPSS, especially ADF unit root test for the following reasons: the underlying distribution theories assumed that the residuals are statistically independent and have constant variance, which may not be true for many time series data; if the length of the time is too long and if the data contains more than one unit root it tends to lose its power to test for stationarity; and, if there is the presence of structural break it tends to meander beyond first difference (as the case of KPSS test for Turkey prices). Because of these shortcomings, literature explicitly showed that scholars viz. Maddalla and Kim (1998) as cited by Gujarati et al.(2012), Maddalla and Lahiri (2013) advocated against the use of the traditional unit root test models- DF, ADF, KPSS and PP (Phillips-Peron test) despite its wide applicability (Sadiq et al. 2017). Thus, due to these possible weaknesses, the corrected ADF test called ADF-GLS (ADF-Generalized least square) unit root test developed by Elliot, Rotenberg and Stock was applied to verify the robustness and efficiency of the 
conventional unit root tests. The results of the ADFGLS test at level showed all the price series to be white noise-non-stationary- as evidenced by their respective tau-statistics which were outside the plausible margin of $5 \%$ degree of freedom. Afterwards, at the first difference, all the market price series became stationary-Gaussian white noise- as indicated by their respective tau-statistics which were within the acceptable margin of 5\% degree of freedom. Based on the ADF-GLS test, the results of the traditional unit root tests are not robust. Therefore, it can be inferred that the selected market price series were integrated of the same order i.e. integrated of order one [I(1)]. Given the integration order of the selected market price series- $[\mathrm{I}(1)]$, a co-integration test was applied to see whether there exist price transmission or not among these markets in the long run to warrant the application of unrestricted VAR or restricted VAR as the case may be. Given the comparable varieties or grades of barley across the chosen markets, it can be assumed that price variability is not caused by grade or variety differences but rather by spatial effects.

Table 2: Unit root tests

\begin{tabular}{|l|l|r|r|r|}
\hline Markets & Stage & ADF & KPSS & ADF-GLS \\
\hline \multirow{3}{*}{ Australia } & Level & $-2.8826(0.054)^{\mathrm{ns}}$ & $1.4317^{\mathrm{ns}}$ & $-2.9887^{\mathrm{ns}}$ \\
\cline { 2 - 5 } & $\mathbf{1}^{\text {st }} \Delta$ & $-6.0694(0.000)^{\mathrm{st}}$ & $0.0602^{\mathrm{st}}$ & $-6.2449^{\mathrm{st}}$ \\
\hline \multirow{3}{*}{ Canada } & Level & $-3.4059(0.011)^{\mathrm{st}}$ & $1.3111^{\mathrm{nt}}$ & $-2.6328^{\mathrm{ns}}$ \\
\cline { 2 - 5 } & $\mathbf{1}^{\text {st }} \Delta$ & - & $0.0602^{\mathrm{st}}$ & $-5.7017^{\mathrm{st}}$ \\
\hline \multirow{3}{*}{ Iran } & Level & $-5.6411(0.000)^{\mathrm{st}}$ & $0.3052^{\mathrm{st}}$ & $-2.1339^{\mathrm{ns}}$ \\
\cline { 2 - 5 } & $\mathbf{1}^{\text {st }} \Delta$ & - & - & $-10.6926^{\mathrm{st}}$ \\
& Level & $-3.1118(0.032)^{\mathrm{st}}$ & $1.8513^{\mathrm{ns}}$ & $-1.1330^{\mathrm{ns}}$ \\
\cline { 2 - 5 } & $\mathbf{1}^{\text {st }} \Delta$ & - & $0.5261^{\mathrm{ns}}$ & $-6.8367^{\mathrm{st}}$ \\
\cline { 2 - 5 } & $\mathbf{2}^{\text {nd }} \Delta$ & - & $0.0203^{\mathrm{st}}$ & - \\
\hline \multirow{2}{*}{ USA } & Level & $-2.7222(0.070)^{\mathrm{ns}}$ & $1.7657^{\mathrm{ns}}$ & $-2.5383^{\mathrm{ns}}$ \\
\cline { 2 - 5 } & $\mathbf{1}^{\text {st } \Delta}$ & $-6.9753(0.000)^{\mathrm{st}}$ & $0.0651^{\mathrm{st}}$ & $-5.3714^{\mathrm{st}}$ \\
\hline
\end{tabular}

Source: Computer printout, 2021

Note: ADF-GLS and KPSS tau critical levels at 5\% probability are -3.19 and 0.462 respectively.

$* * * * * *$ ns, st $\& \Delta$ mean significant at $1,5,10 \%$, Non-significant, non-stationary, stationary and first difference respectively. Value in parenthesis is probability level.

\section{The extent of Price Transmission}

A perusal of the bivariate co-integration results showed market pairs viz. Australia-Canada, Australia-Iran, Australia-USA; Canada-Iran, CanadaUSA; and, Iran-Turkey and Iran-USA to have twoway causal co-integration as indicated by their respective $\mathrm{ADF}$ unit root test statistics of the cointegration regression residuals which are less than the Engle-Granger critical value at 5\% significance level (Table 3). However, except for Iran market prices, Turkey market prices was independent i.e. is not integrated with the prices of all the remaining selected markets as evidenced by their respective ADF unit root test absolute statistics of the co-integrating regression residuals which were lower than the EngleGranger critical value at 5\% probability level. Thus, it can be inferred that the barley market prices are well connected across the international market. Furthermore, out of the twenty relationships, only fourteen were co-integrated, thus indicating a high level of integration-price communication in the international barley markets of the world.

Table 3: Engle and Granger co-integration test

\begin{tabular}{|l|l|l|l|l|l|}
\hline Markets & Australia & Canada & Iran & Turkey & USA \\
\hline Australia & - & $-3.8421^{*}$ & $-4.4585^{*}$ & $-2.463^{\mathrm{ns}}$ & $-4.0419^{*}$ \\
\hline Canada & $-3.8342^{*}$ & - & $-4.4386^{*}$ & $-1.9582^{\mathrm{ns}}$ & $-3.9430^{*}$ \\
\hline Iran & $-4.6428^{*}$ & $-4.6353^{*}$ & & $-3.6076^{*}$ & $-4.6185^{*}$ \\
\hline Turkey & $-2.3745^{\mathrm{ns}}$ & $-1.9004^{\mathrm{ns}}$ & $-3.3927^{*}$ & - & $-2.1989^{\mathrm{ns}}$ \\
\hline USA & $-4.0372^{*}$ & $-3.9475^{*}$ & $-4.4233^{*}$ & - & $-2.2818^{\mathrm{ns}}$ \\
\hline
\end{tabular}

Source: Computer printout, 2021

Note: Engle and Granger critical value at $5 \%$ probability is -3.37 . * \& ${ }^{\text {ns }}$ indicate significant at 5\% and non-significant respectively. 
However, due to the limitation of the EngleGranger test to test for multiple co-integration, Johansen maximum likelihood co-integration method was adopted to determine the number of co-integrating price series from a range of five markets price series (Table 4). A cursory review of the Johansen cointegration test results showed both the trace and maxeigen tests to have four co-integrating vectors (the market price series were co-integrated at rank four) and one common trend as evidenced by their respective first three statistical values which were different from zero at 5\% probability level and the last statistical value that was not different from zero at 5\% significance level. This means that out of the five selected markets, only four markets were integrated. Thus, it can be argued that there exist four cointegrating vectors, alongside one common stochastic trend among the five selected barley markets in the world. The presence of one common stochastic trend indicates the presence of pair-wise co-integration of prices, inferring that the law of one price (LOP) holds among these markets despite been spatially and geographically far apart. This suggests that four market prices are strongly co-integrated and converge to long-run equilibrium in the sense that the international barley market system is stationary in four directions and non-stationary in one direction. Thus, the Johansen co-integration test has shown that despite the selected barley markets are spatially segmented and geographical isolated, they are well-connected in terms of barley prices, indicating that the selected barley markets have long-run price linkage/association across them. Succinctly, it means that the prices of these selected markets move together in the long run. Generally, the results of the co-integration tests viz. bivariate and multivariate co-integration tests indicated that in the long run, the international barley markets are strongly co-integrated as four out of the five selected markets were co-integrated. Besides, it indicates that one common stochastic trend; hence one independent market exists among the five selected markets. Given that the market prices are integratedwell-connected: price series meander together in the long run, restricted VAR was applied to check whether these markets established long-run equilibrium.

Table 4: Multivariate horizontal-wise co-integration

\begin{tabular}{|c|rr|r|r|r|}
\hline Rank & Eigen value & \multicolumn{1}{l|}{ Trace test } & \multicolumn{1}{l|}{ P-value } & \multicolumn{1}{l|}{ Lmax test } & \multicolumn{1}{l|}{ P-value } \\
\hline 0 & 0.61709 & $112.03^{* *}$ & 0.0000 & $47.037^{* *}$ & 0.0001 \\
\hline 1 & 0.47607 & $64.996^{* *}$ & 0.0000 & $31.673^{* *}$ & 0.0027 \\
\hline 2 & 0.33384 & $33.323^{* *}$ & 0.0023 & $19.905^{* *}$ & 0.0213 \\
\hline 3 & 0.23481 & $13.418^{* *}$ & 0.0317 & $13.114^{* *}$ & 0.0214 \\
\hline 4 & 0.00618 & 0.3041 & 0.6536 & 0.3041 & 0.6447 \\
\hline
\end{tabular}

Source: Computer printout, 2021

Note: **denotes rejection of the null hypothesis at 5 percent level of significance

\section{Degree of Market Integration}

The VECM results showed that only the market price series of Australia and Canada established long-run equilibrium as indicated by their respective attractor coefficients- error coefficient terms (ECTs) which were within the acceptable margin of $10 \%$ probability level (Table 5). Thus, it can be inferred that these markets are efficient in the degree of their price transmission as their prices are stable in the long run. Besides, a price shock that induces price deviation from their respective equilibrium will induce traders to respond to the shock in such a way that prices will converge towards their equilibrium. In other words, it implies that disequilibrium-deviation from the long-run equilibrium due to any shock that emanated from the short-run dynamics are well corrected/adjusted so that equilibrium is re-established. The coefficients of the speed of adjustments for Australian and Canadian prices are -0.791 and -0.357 respectively, indicating that 0.791 and $0.357 \%$ of divergences from the longrun equilibrium for the former and latter were been corrected annually. These show that it will take Australian and Canadian market prices respectively, approximately 9.5 and 4.3 months to re-established long-run equilibrium in case of any shock that occurs in the short run. The process of adjustment of the Australian price series was relatively faster and this might be due to the lesser transaction and transfer costs that owe to proximity and better infrastructure. However, the process of adjustment in the price series of Canadian barley is relatively low and might be attributed to high transaction and transfer costs which may be due to internal trade policies.

The market prices of Iran, Turkey and the USA were not stable in the long run as indicated by their respective speed of adjustment coefficients which were not different from zero at a $10 \%$ degree of freedom. Thus, it can be inferred that these markets are autarkic markets given that their prices are not stable in the long run. The possible reasons for the poor degree of market integration may be due to high transactional and transfer costs relative to the price differential between markets; inventory accumulation- 
leverage effect: price variations send signals to inventory holders that make them accumulate or reduce stocks; risk aversion; market information failures; and, menu costs: costs that result from repricing and information process that the producers face in the presence of exogenous variations, thus causing a discontinuity in a price adjustment. These factors create more friction in the arbitrage process, thus affected the degree of price stability in these markets.

Except for the price series of the Turkey market, all the remaining market price series have negative attractor coefficients. These coefficients reflect that the short-run dynamics moves toward the equilibrium while the positive signed ECT reflects the short-run deviation of the system from the equilibrium level. In addition, the negative ECT indicates that the short-run disequilibrium adjustment might lead to stable long-run prices in Australian, Canadian, Iranian and USA markets. However, the positive ECT of the
Turkey market price series implies that the short-run disequilibrium adjustment might not lead to stable long-run prices.

The diagnostic tests of the price series residuals for the estimated model showed the absence of serial correlation and ARCH effect as evidenced by their respective Ljung-Box Q statistics and langrage multiplier test statistics which were not different from zero at a $10 \%$ degree of freedom. However, the residual of the estimated model was not normally distributed as indicated by its respective $\mathrm{Chi}^{2}$ test statistic which is different from zero at a $10 \%$ degree of freedom. Though, literature has shown that nonnormality in the distribution of the residual is not considered a serious problem as data in their natural form are mostly not normally distributed (Sadiq et al., 2016; 2017 and 2018). Thus, the estimated parameters are reliable for prediction with accuracy and consistency. In addition, the model is fit for the specified equation.

Table 5: Degree of market integration

\begin{tabular}{|c|c|c|}
\hline Variable & $\Delta$ Australia & $\Delta$ Canada \\
\hline $\mathrm{EC}_{\mathrm{t}-1}$ & $-0.790515(0.167465)[4.720]^{* * *}$ & $-0.356489(0.188230)[1.894]^{*}$ \\
\hline $\mathrm{EC}_{\mathrm{t}-2}$ & $-0.226402(0.214133)[1.057]^{\mathrm{NS}}$ & $-0.832148(0.240684)[3.457]^{* * *}$ \\
\hline $\mathrm{EC}_{\mathrm{t}-3}$ & $0.012910(0.032260)[0.400]^{\mathrm{NS}}$ & $0.057939(0.036260)[1.598]^{\mathrm{NS}}$ \\
\hline $\mathrm{EC}_{\mathrm{t}-4}$ & $-0.092615(0.042292)[2.190]^{* *}$ & $-0.126739(0.0475364)[2.666]^{* *}$ \\
\hline D-W stat & 1.622 & 1.6813 \\
\hline Autocorrelation $\left(\mathrm{Chi}^{2}\right)$ & $1.780\{0.182\}^{\mathrm{NS}}$ & $0.812\{0.367\}^{\mathrm{NS}}$ \\
\hline \multirow[t]{2}{*}{ Arch effect (LM test) } & $15.18\{0.649\}^{\mathrm{NS}}$ & $18.38\{0.430\}^{\mathrm{NS}}$ \\
\hline & $\Delta$ Iran & $\Delta$ Turkey \\
\hline $\mathrm{EC}_{\mathrm{t}-1}$ & $-0.500296(0.827611)[-0.604]^{\mathrm{NS}}$ & $0.0349489(0.157374)[0.222]^{\mathrm{NS}}$ \\
\hline $\mathrm{EC}_{\mathrm{t}-2}$ & $-1.87927(1.05824)[1.776]^{*}$ & $0.198535(0.201229)[0.986]^{\mathrm{NS}}$ \\
\hline $\mathrm{EC}_{\mathrm{t}-3}$ & $-0.763510(0.159431)[4.789]^{* * *}$ & $-0.0151515(0.0303165)[0.499]^{\mathrm{NS}}$ \\
\hline $\mathrm{EC}_{\mathrm{t}-4}$ & $-0.152685(0.209008)[0.730]^{\mathrm{NS}}$ & $-0.115072(0.0397438)[2.895]^{* * *}$ \\
\hline D-W stat & 2.029 & 1.966 \\
\hline Autocorrelation $\left(\mathrm{Chi}^{2}\right)$ & $0.019\{0.888\}^{\mathrm{NS}}$ & $0.005\{0.944\}^{\mathrm{NS}}$ \\
\hline \multirow[t]{2}{*}{ Arch effect (LM test) } & $0.957\{1.00\}^{\mathrm{NS}}$ & $16.30\{0.571\}^{\mathrm{NS}}$ \\
\hline & $\Delta \mathrm{USA}$ & \\
\hline $\mathrm{EC}_{\mathrm{t}-1}$ & $-0.238157(0.160808)[1.481]^{\mathrm{NS}}$ & \\
\hline $\mathrm{EC}_{\mathrm{t}-2}$ & $-0.0387670(0.205621)[0.188]^{\mathrm{NS}}$ & \\
\hline $\mathrm{EC}_{\mathrm{t}-3}$ & $0.0300465(0.0309782)[0.969]^{\mathrm{NS}}$ & \\
\hline $\mathrm{EC}_{\mathrm{t}-4}$ & $-0.0446643(0.0406113)[1.100]^{\mathrm{NS}}$ & \\
\hline D-W stat & 1.651 & \\
\hline Autocorrelation $\left(\mathrm{Chi}^{2}\right)$ & $1.3708\{0.242\}^{\mathrm{NS}}$ & \\
\hline Arch effect (LM test) & $18.86\{0.399\}^{\mathrm{NS}}$ & \\
\hline Normality $\left(\mathrm{Chi}^{2}\right)$ & $84.91\{0.000\} * * *$ & \\
\hline
\end{tabular}

Source: Computer printout, 2021

Note: $* * * * * \&$ NS means significant at $1 \%, 5 \%, 10 \%$ and non-significant respectively

Values in ( ); [ ] and \{ \} are standard error, t-statistic and probability value

\section{Price Formation}

The granger causality results showed two significant F-statistics for the Australian price series; while Canada and USA price series had one significant F-statistics each at a 5\% probability level (Table 6).
Based on the Granger causality test, bidirectional causality exists between the market pair of CanadaUSA; while the market pairs of Australia-Turkey and Australia-USA had unidirectional causalities as indicated by their respective F-statistics which were 
within the acceptable margin of 5\% probability level. However, the market pairs viz. Australia-Canada, Australia-Iran, Canada-Iran, Canada-Turkey, IranTurkey, Iran-USA, and Turkey-USA have no causal relationship as evidenced by their respective Fstatistics that were not different from zero at 5\% probability level. For the market pair with bidirectional causality, it means that event of a price change in the former market in the pair granger causes a price formation in the latter market which in turn provides feedback to the former market. For the market pairs that exhibit a unidirectional causality, it means that the former market in each pair contains useful information that predicts the future price of the latter market while the latter market doesn't contain useful information to predict the future of the former. However, for the market pairs with no causal relationship, it implies that neither the former market in each pair granger causes the price formation in the latter market nor the latter market granger causes price formation in the former market. Furthermore, the empirical evidence showed Australia and Iran markets to be independent markets (exogenous to all markets), thus not influenced by any event of price changes from its contemporary markets. Succinctly, it can be inferred that the international boundary has little influence in segmenting the market pair of Canada and USA; while Australia and Iran's markets are large consumer markets. Besides, Iran and Australian markets are important sources of price formation in the international barley market. Except for the Australian market, the Turkey market was exogenous to most of the markets; except the Canadian market, the USA market was exogenous to all the remaining markets; likewise, except the USA market, the Canada market was exogenous to all the remaining markets. Thus, it can be concluded that Canada, the USA and Turkey markets are import and export hubs of barley in the world. Of the ten relationships, seven relationships were strongly exogenous to the system. Contrary to Engle and Granger causality test, the Granger causality test showed that most of the markets are independent of each other and not integrated into the long run.

Table 6: Horizontal pair-wise Granger causality test

\begin{tabular}{|c|c|c|c|c|}
\hline Null hypothesis & F-stat & $P<0.05$ & Granger cause & Direction \\
\hline \multirow{2}{*}{$A U S T \leftrightarrow C A N$} & 1.0977 & $0.3008^{\mathrm{NS}}$ & No & \multirow{2}{*}{ None } \\
\hline & .66004 & $0.4211^{\mathrm{NS}}$ & No & \\
\hline \multirow[t]{2}{*}{$A U S T \leftrightarrow I R A N$} & .2562 & $0.6154^{\mathrm{NS}}$ & No & \multirow[t]{2}{*}{ None } \\
\hline & .2558 & $0.6157^{\mathrm{NS}}$ & No & \\
\hline \multirow[t]{2}{*}{$A U S T \leftrightarrow T U R K E Y$} & 5.1136 & $0.0290^{* *}$ & Yes & \multirow[t]{2}{*}{ Unidirectional } \\
\hline & .20525 & $0.6529^{\mathrm{NS}}$ & No & \\
\hline \multirow[t]{2}{*}{$A U S T \leftrightarrow U S A$} & 9.9476 & $0.0030^{* *}$ & Yes & \multirow[t]{2}{*}{ Unidirectional } \\
\hline & 2.7275 & $0.1061^{\mathrm{NS}}$ & No & \\
\hline \multirow{2}{*}{$C A N \leftrightarrow I R A N$} & .16122 & $0.6901^{\mathrm{NS}}$ & No & \multirow{2}{*}{ None } \\
\hline & 1.2887 & $0.2627^{\mathrm{NS}}$ & No & \\
\hline \multirow[t]{2}{*}{$C A N \leftrightarrow T U R K E Y$} & 3.6484 & $0.0630^{\mathrm{NS}}$ & No & \multirow[t]{2}{*}{ None } \\
\hline & 3.9543 & $0.0533^{\mathrm{NS}}$ & No & \\
\hline \multirow{2}{*}{$C A N \leftrightarrow U S A$} & 4.4246 & $0.0415^{* *}$ & Yes & \multirow{2}{*}{ Bidirectional } \\
\hline & 6.4021 & $0.0152 * *$ & Yes & \\
\hline \multirow[t]{2}{*}{$I R A N \leftrightarrow T U R K E Y$} & .49589 & $0.4852^{\mathrm{NS}}$ & No & \multirow[t]{2}{*}{ None } \\
\hline & .65433 & $0.4231^{\mathrm{NS}}$ & No & \\
\hline \multirow[t]{2}{*}{$I R A N \leftrightarrow U S A$} & 3.1596 & $0.0827^{\mathrm{NS}}$ & No & \multirow[t]{2}{*}{ None } \\
\hline & .02483 & $0.8756^{\mathrm{NS}}$ & No & \\
\hline \multirow[t]{2}{*}{ TURKEY $\leftrightarrow U S A$} & .03497 & $0.8526^{\mathrm{NS}}$ & No & \multirow[t]{2}{*}{ None } \\
\hline & 1.0925 & $0.3019^{\mathrm{NS}}$ & No & \\
\hline$A U S T \rightarrow A L L$ & 7.6482 & $0.0001 * *$ & Yes & Multidirectional \\
\hline$C A N \rightarrow A L L$ & 2.1 & $0.0978^{\mathrm{NS}}$ & No & None \\
\hline$I R A N \rightarrow A L L$ & .84825 & $0.5027^{\mathrm{NS}}$ & No & None \\
\hline TURKEY $\rightarrow$ ALL & 2.5059 & $0.0564^{\mathrm{NS}}$ & No & None \\
\hline$U S A \rightarrow A L L$ & 2.8321 & $0.0363 * *$ & Yes & Multidirectional \\
\hline$U S A \rightarrow A L L$ & 3.1623 & 0.036* & Yes & Multidirectional \\
\hline
\end{tabular}

Source: Computer printout, 2021

Note: $* *$ denotes rejection of the $\mathrm{H}_{0}$ at $5 \%$ level of significance; NS: Non-significant

$\rightarrow \leftarrow$ means forward and backward directions respectively 


\section{Effect of Price Shock}

The impulse function results reveal how and to what extent a standard deviation shock in one of the barley markets affects the current as well as the future prices in all the integrated markets over a period of ten years (Figure 1). The graphs indicate that unexpected shocks that are local to the average price of Australian barley will die out in all the other markets while an orthogonalized shock to the average price of Canadian barley will have a permanent effect on all the average barley prices of all the selected markets. Unexpected shocks that are local to the average barley prices of Iranian barley will have a permanent effect on the average barley prices of Australian and USA markets; while it will have a transitory effect on the average barley prices of Canadian, Iranian and Turkey markets. Besides, an unexpected shock that is local to the average barley prices of the Turkey market will not die out in the Iranian market but will die out in all the remaining contemporary markets (including its market). An orthogonalized shock to the average barley prices of the USA will have a permanent effect on all the selected markets. A shock that originates from Canadian and USA markets are more transmitted to all the other markets while a shock that originates from other markets are less transmitted to the USA market. This means that Canadian and USA markets have a dominant influence in price determination of the other selected international markets. However, it is worth noting that the influence proportion of Canadian price shock is more than that of the USA market given that Iranian price shock will not die out in the latter market as time passes. Unlike Turkey, the Australian market is a relatively market follower as a shock given to this market is fewer transmitted-dies out over time in all the other markets. Thus, it can be inferred that Canadian and USA markets are the major markets that play a significant role in the international barley market while the Australian market did not play a significant role in the international barley market.

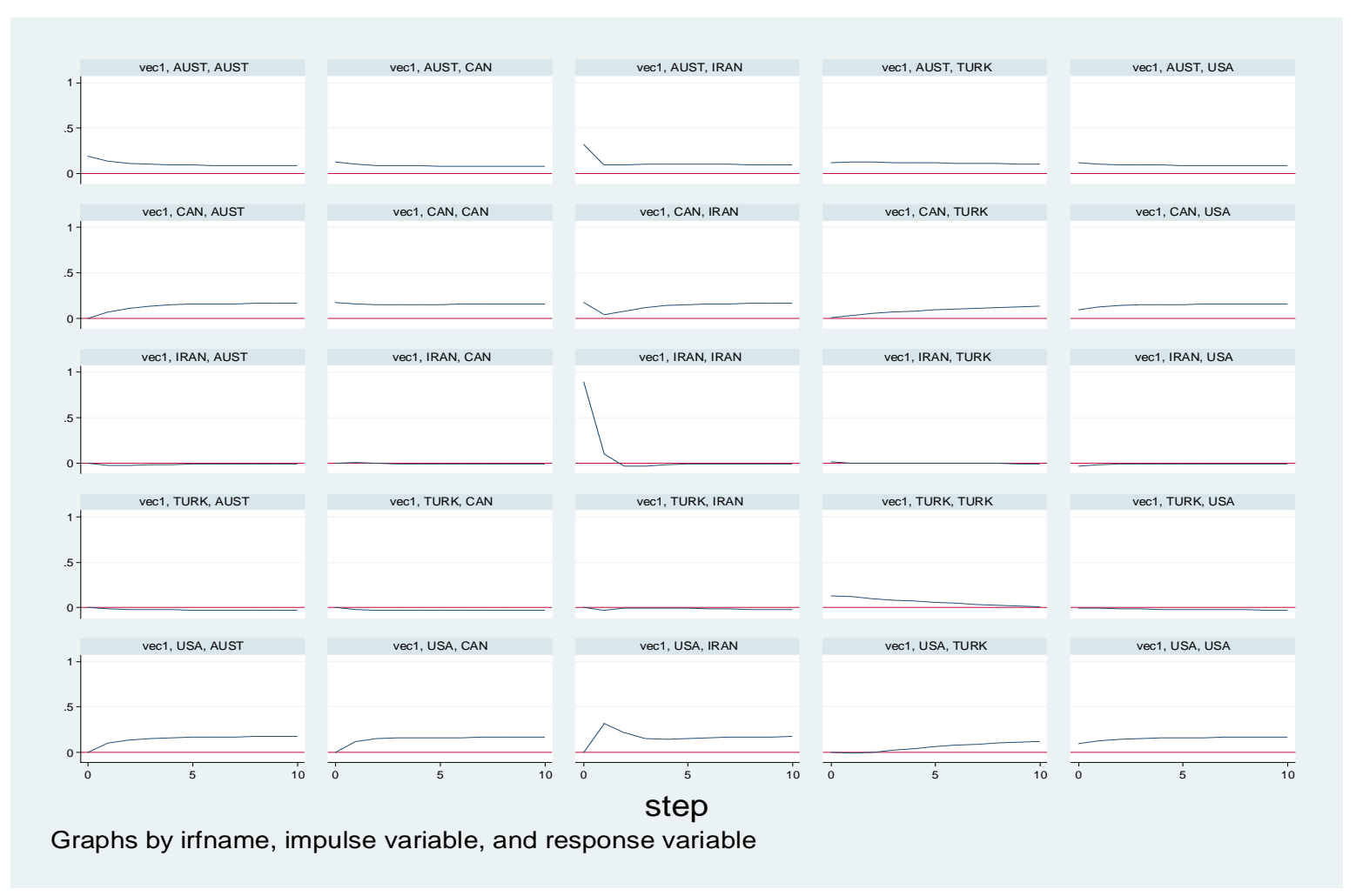

Figure 1: Impulse response function of the market prices

\section{Variance Decomposition of the Price Series}

The variance decomposition results showed that in the short-run $\left(5^{\text {th }}\right.$ period $)$, a shock that originates from the Australian market accounts for 38.12, 25.70 and $34.67 \%$ variation in the average barley prices of
Australia, Canada and the USA markets respectively (Table 7). While a price shock in the long-run $\left(10^{\text {th }}\right.$ period) accounts for 23.50, 34.23 and $40.86 \%$ variations in the average market prices of Australia, 
Canada and the USA respectively. However, the percentage effect of shock both in the short and longruns from the Australian market on average barley price variations of Iran and Turkey were very marginal (less than 1\%). In the same vein, the effect of a price shock in the Canadian market on the average market prices of Australia, Canada and the USA respectively, are $18.71,46.40$ and $33.92 \%$ in the short-run; and, $15.22,43.37$ and $40.18 \%$ in the long-run. The effect of the Canadian market price shock is very marginal (less than 1) on the average barley prices of Iran and Turkey markets both in the short and long runs. Furthermore, the effect of price shock of the average barley prices of Iranian market both in the short and long-run causes marginal variation in the average barley prices of Turkey; low variation in the average barley prices of Australia, Canada and USA; and, high variation in the average barley prices of its market.

The effect of price shock in the Turkey market causes high variation in the average prices of the Australian market both in the short and long-runs; high and low price variations respectively in the short-run and longrun in its market (Turkey); and, a very marginal price variation both in the short and long-runs in the Iranian market. In the USA market, the price variation due to induced price shock from Turkey market is 1.80 and $13.69 \%$ respectively, in short, and long-runs. The variation due to the effect of price shock in the USA market is moderate both in the short and long-runs in the Australian market; high in Canadian and USA markets both in the short and long-runs; and, very marginal in Iranian and Turkey markets both in the short and long-runs. Therefore, it can be inferred that price shocks in Australian, Canadian and USA markets have a relatively less effect on average price variations in Iran and Turkey markets. While Australian price shock effect has a relatively high effect on the average prices of Canada and USA markets. It is noteworthy to point that the effect of price shock between Canada and USA markets on each other's price variation is simultaneous-high. 
Table 7: Variance decomposition of the price series

\begin{tabular}{|c|c|c|c|c|c|c|c|c|c|c|}
\hline \multirow[t]{2}{*}{ Period } & \multicolumn{5}{|c|}{ Australia market } & \multicolumn{5}{|c|}{ Canada market } \\
\hline & Australia & Canada & Iran & Turkey & USA & Australia & Canada & Iran & Turkey & USA \\
\hline 1 & 100.00 & 0.00 & 0.00 & 0.00 & 0.00 & 36.89 & 63.10 & 0.00 & 0.00 & 0.00 \\
\hline 2 & 76.35 & 6.71 & 0.95 & 0.26 & 15.70 & 28.54 & 56.46 & 0.08 & 0.36 & 14.53 \\
\hline 3 & 57.52 & 15.02 & 1.12 & 0.45 & 25.87 & 23.33 & 51.04 & 0.06 & 0.61 & 24.94 \\
\hline 4 & 45.67 & 21.35 & 0.99 & 0.57 & 31.39 & 20.44 & 48.07 & 0.09 & 0.75 & 30.62 \\
\hline 5 & 38.12 & 25.69 & 0.84 & 0.66 & 34.67 & 18.70 & 46.39 & 0.12 & 0.84 & 33.92 \\
\hline 6 & 33.07 & 28.65 & 0.73 & 0.72 & 36.81 & 17.55 & 45.34 & 0.14 & 0.90 & 36.04 \\
\hline 7 & 29.54 & 30.72 & 0.64 & 0.78 & 38.30 & 16.72 & 44.62 & 0.15 & 0.95 & 37.53 \\
\hline 8 & 26.97 & 32.22 & 0.58 & 0.82 & 39.38 & 16.10 & 44.09 & 0.16 & 0.99 & 38.64 \\
\hline 9 & 25.02 & 33.35 & 0.53 & 0.86 & 40.21 & 15.61 & 43.68 & 0.17 & 1.02 & 39.49 \\
\hline 10 & 23.50 & 34.23 & 0.49 & 0.90 & 40.86 & 15.21 & 43.36 & 0.17 & 1.05 & 40.18 \\
\hline \multirow[t]{2}{*}{ Period } & \multicolumn{5}{|c|}{ Iran market } & \multicolumn{5}{|c|}{ Turkey market } \\
\hline & Australia & Canada & Iran & Turkey & USA & Australia & Canada & Iran & Turkey & USA \\
\hline 1 & 10.92 & 3.23 & 85.84 & 0.00 & 0.00 & 45.16 & 0.33 & 0.40 & 54.09 & 0.00 \\
\hline 2 & 10.58 & 2.97 & 76.62 & 0.06 & 9.76 & 48.15 & 1.84 & 0.20 & 49.68 & 0.10 \\
\hline 3 & 10.82 & 3.40 & 72.44 & 0.06 & 13.27 & 50.28 & 4.15 & 0.14 & 45.32 & 0.09 \\
\hline 4 & 11.30 & 4.53 & 69.32 & 0.05 & 14.77 & 51.37 & 6.93 & 0.11 & 41.00 & 0.58 \\
\hline 5 & 11.74 & 6.00 & 66.28 & 0.05 & 15.91 & 51.43 & 9.96 & 0.09 & 36.71 & 1.79 \\
\hline 6 & 12.07 & 7.54 & 63.28 & 0.06 & 17.03 & 50.63 & 13.06 & 0.07 & 32.56 & 3.65 \\
\hline 7 & 12.31 & 9.06 & 60.38 & 0.06 & 18.16 & 49.20 & 16.05 & 0.07 & 28.70 & 5.95 \\
\hline 8 & 12.49 & 10.51 & 57.63 & 0.07 & 19.27 & 47.36 & 18.84 & 0.07 & 25.21 & 8.50 \\
\hline 9 & 12.62 & 11.88 & 55.04 & 0.09 & 20.35 & 45.30 & 21.36 & 0.07 & 22.13 & 11.11 \\
\hline 10 & 12.72 & 13.16 & 52.62 & 0.11 & 21.38 & 43.16 & 23.59 & 0.08 & 19.46 & 13.69 \\
\hline \multirow[t]{2}{*}{ Period } & \multicolumn{5}{|c|}{ USA market } & & & & & \\
\hline & Australia & Canada & Iran & Turkey & USA & & & & & \\
\hline 1 & 41.08 & 28.07 & 3.25 & 0.00 & 27.57 & & & & & \\
\hline 2 & 32.84 & 32.59 & 1.82 & 0.08 & 32.64 & & & & & \\
\hline 3 & 27.77 & 34.93 & 1.25 & 0.16 & 35.87 & & & & & \\
\hline 4 & 24.56 & 36.34 & 0.96 & 0.23 & 37.88 & & & & & \\
\hline 5 & 22.41 & 37.28 & 0.79 & 0.30 & 39.20 & & & & & \\
\hline 6 & 20.88 & 37.93 & 0.68 & 0.37 & 40.13 & & & & & \\
\hline 7 & 19.73 & 38.40 & 0.60 & 0.42 & 40.82 & & & & & \\
\hline 8 & 18.84 & 38.75 & 0.54 & 0.48 & 41.37 & & & & & \\
\hline 9 & 18.12 & 39.01 & 0.50 & 0.53 & 41.82 & & & & & \\
\hline 10 & 17.54 & 39.21 & 0.47 & 0.57 & 42.19 & & & & & \\
\hline
\end{tabular}

Source: Computer print-out, 2021 


\section{Price Forecast of the Selected Markets}

By the one-step-ahead prediction, the validity of the predictive power of the best fit VECM was tested and how closely they could follow the course of the actual observations (Table 8).

Table 8: One step ahead forecast of prices

\begin{tabular}{|c|c|c|c|c|c|c|}
\hline \multirow[t]{2}{*}{ Year } & \multicolumn{2}{|c|}{ Australia market } & \multicolumn{2}{|c|}{ Canada market } & \multicolumn{2}{|c|}{ Iran market } \\
\hline & Actual & Predict & Actual & Predict & Actual & Predict \\
\hline 2015 & 210.398 & 255.25 & 174.10 & 181.46 & 304.10 & 421.30 \\
\hline 2016 & 188.10 & 262.72 & 166.30 & 205.34 & 276.30 & 493.92 \\
\hline 2017 & 150.99 & 231.29 & 148.80 & 186.22 & 295.40 & 394.59 \\
\hline 2018 & 183.79 & 202.87 & 163.90 & 175.61 & 288.50 & 393.16 \\
\hline \multirow[t]{3}{*}{2019} & 237.69 & 218.09 & 169.70 & 177.08 & 192.00 & 338.85 \\
\hline & \multicolumn{2}{|c|}{ Turkey market } & \multicolumn{2}{|c|}{ USA market } & & \\
\hline & Actual & Predict & Actual & Predict & & \\
\hline 2015 & 237.20 & 288.88 & 254.00 & 247.18 & & \\
\hline 2016 & 224.90 & 246.10 & 228.00 & 271.27 & & \\
\hline 2017 & 212.80 & 234.16 & 205.00 & 242.66 & & \\
\hline 2018 & 177.80 & 218.13 & 212.00 & 224.86 & & \\
\hline 2019 & 189.00 & 190.51 & 211.00 & 224.88 & & \\
\hline
\end{tabular}

Source: Authors' computation, 2021

Furthermore, as indicated by Theil's coefficient of inequality $(\mathrm{U})$ and the relative mean absolute prediction error (RMAPE) within the range of 1 and 5\% respectively (Table 9), the accuracy of the VECM was found to be predictive. Therefore, the VECM can be used for the ex-ante forecast with high forecast validity and precision as the predictive error associated with the predicted equation is negligible and low in the actual data monitoring (ex-post prediction).

Table 9: Validation of models

\begin{tabular}{|l|l|l|l|l|l|l|}
\hline Market & $\mathbf{R}^{\mathbf{2}}$ & MAPE & RMSPE & RMAPE (\%) & RMSE & Theil's U \\
\hline Australia & 0.970586 & -0.15465 & 0.012156 & -3.03999 & 0.249248 & 0.358431 \\
\hline Canada & 0.978563 & -0.10937 & 0.004009 & -2.15833 & 0.142394 & 0.002627 \\
\hline Iran & 0.937457 & -0.34961 & 0.030612 & -6.3386 & 0.40983 & 0.156451 \\
\hline Turkey & 0.985065 & -0.07966 & 0.002258 & -1.50971 & 0.40983 & 0.184791 \\
\hline USA & 0.982774 & -0.09301 & 0.002463 & -1.7319 & 0.115045 & 0.657663 \\
\hline
\end{tabular}

Source: Authors computation, 2021

One-step-ahead out of sample forecast of the selected market prices are shown in Table 12 and Figure (2-6). The empirical evidence showed that the market prices of Australia will witness a marginal rise that will stagnant at two different intervals. In the year 2020, there was a marginal increase in the price of Australian barley which thereafter plummeted, persists but stagnant till the year 2023. Afterwards, the prices will plummet and remain stagnant till the year 2026. In the subsequent year (2027), the market price of Australian barley will slightly rise and remains stagnant till the end of the forecasted period. In the case of Canadian barley, the market prices will witness a slight decrease that will remain stagnant and persist till the end of the forecasted period. The market prices of Iranian barley will be marked by a slight rise through the first three periods and thereafter will remain stagnant throughout the forecasted period. The market prices of Turkey barley will witness a gentle rise and will persist till the end of the forecasted period. The market prices of
USA barley will witness both gentle fall and rise and will stagnant at two intervals. In the first instance, the market prices of USA barley will slightly plummet (the year 2021) and thereafter rise persistently and then stagnant from the year 2024 to 2026. Afterwards, the price increase will persist and will remain stagnant till the end of the forecasted period. Therefore, it can be inferred that the future prices of barley in the selected international markets will be stable with little inflation which may be attributed to fluctuation in the supply of barley. 
Table 9: Out of sample price forecast of the selected markets (\$ per ton)

\begin{tabular}{|c|c|c|c|c|c|c|c|c|c|}
\hline \multirow[t]{2}{*}{ Year } & \multicolumn{3}{|c|}{ Australia market } & \multicolumn{3}{|c|}{ Canada market } & \multicolumn{3}{|c|}{ Iran market } \\
\hline & Forecast & LCL & UCL & Forecast & UCL & LCL & Forecast & LCL & UCL \\
\hline 2020 & 224.72 & 155.85 & 324.01 & 156.60 & 103.79 & 236.27 & 247.2817 & 40.53 & 1508.54 \\
\hline 2021 & 220.28 & 132.44 & 366.40 & 154.46 & 85.80 & 278.07 & 290.46 & 42.33 & 1992.91 \\
\hline 2022 & 218.10 & 114.03 & 417.14 & 154.55 & 73.96 & 322.96 & 304.69 & 41.96 & 2212.01 \\
\hline 2023 & 217.04 & 99.39 & 473.93 & 154.83 & 65.23 & 367.51 & 307.99 & 40.54 & 2339.69 \\
\hline 2024 & 216.66 & 87.72 & 535.15 & 155.03 & 58.39 & 411.63 & 309.49 & 38.89 & 2462.95 \\
\hline 2025 & 216.66 & 78.27 & 599.71 & 155.18 & 52.82 & 455.93 & 311.15 & 37.23 & 2600.05 \\
\hline 2026 & 216.83 & 70.49 & 666.96 & 155.32 & 48.16 & 500.83 & 312.97 & 35.61 & 2750.59 \\
\hline 2027 & 217.07 & 63.97 & 736.61 & 155.43 & 44.20 & 546.59 & 314.74 & 34.01 & 2912.16 \\
\hline 2028 & 217.33 & 58.41 & 808.58 & 155.54 & 40.77 & 593.38 & 316.38 & 32.46 & 3083.34 \\
\hline 2029 & 217.57 & 53.61 & 882.90 & 155.64 & 37.77 & 641.30 & 317.85 & 30.95 & 3263.51 \\
\hline 2030 & 217.80 & 49.43 & 959.65 & 155.73 & 35.12 & 690.45 & 319.17 & 29.50 & 3452.46 \\
\hline \multirow[t]{2}{*}{ Year } & \multicolumn{3}{|c|}{ Turkey market } & \multicolumn{3}{|c|}{ USA market } & & & \\
\hline & Forecast & LCL & UCL & Forecast & LCL & UCL & & & \\
\hline 2020 & 205.66 & 145.82 & 290.07 & 206.83 & 145.55 & 293.91 & & & \\
\hline 2021 & 217.23 & 134.51 & 350.82 & 205.71 & 121.40 & 348.58 & & & \\
\hline 2022 & 226.77 & 127.30 & 403.97 & 205.85 & 104.80 & 404.35 & & & \\
\hline 2023 & 235.33 & 121.91 & 454.25 & 206.41 & 92.29 & 461.67 & & & \\
\hline 2024 & 243.12 & 117.18 & 504.39 & 207.09 & 82.38 & 520.58 & & & \\
\hline 2025 & 250.19 & 112.55 & 556.16 & 207.78 & 74.28 & 581.21 & & & \\
\hline 2026 & 256.58 & 107.79 & 610.74 & 208.42 & 67.48 & 643.72 & & & \\
\hline 2027 & 262.33 & 102.86 & 668.97 & 209.01 & 61.68 & 708.28 & & & \\
\hline 2028 & 267.49 & 97.82 & 731.45 & 209.55 & 56.65 & 775.01 & & & \\
\hline 2029 & 272.11 & 92.72 & 798.57 & 210.02 & 52.26 & 844.04 & & & \\
\hline 2030 & 276.24 & 87.64 & 870.64 & 210.44 & 48.37 & 915.49 & & & \\
\hline
\end{tabular}

Source: Computer print-out, 2021 

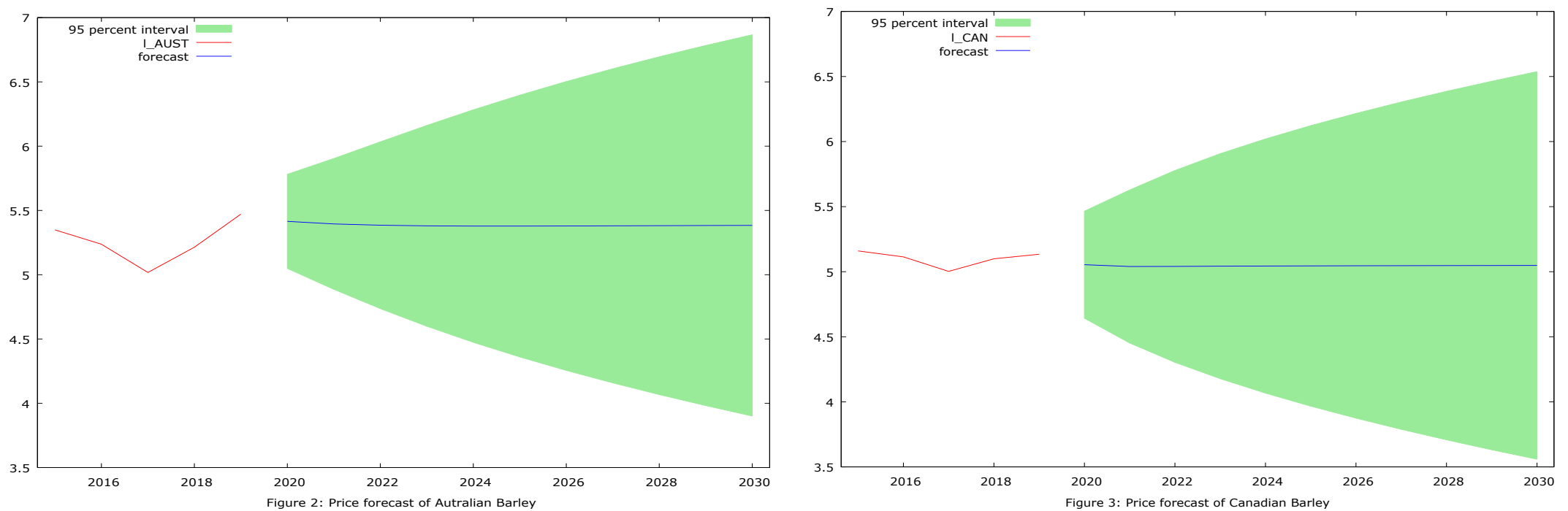

Figure 2: Price forecast of Australian barley

Figure 3: Price forecast of Canadian barley
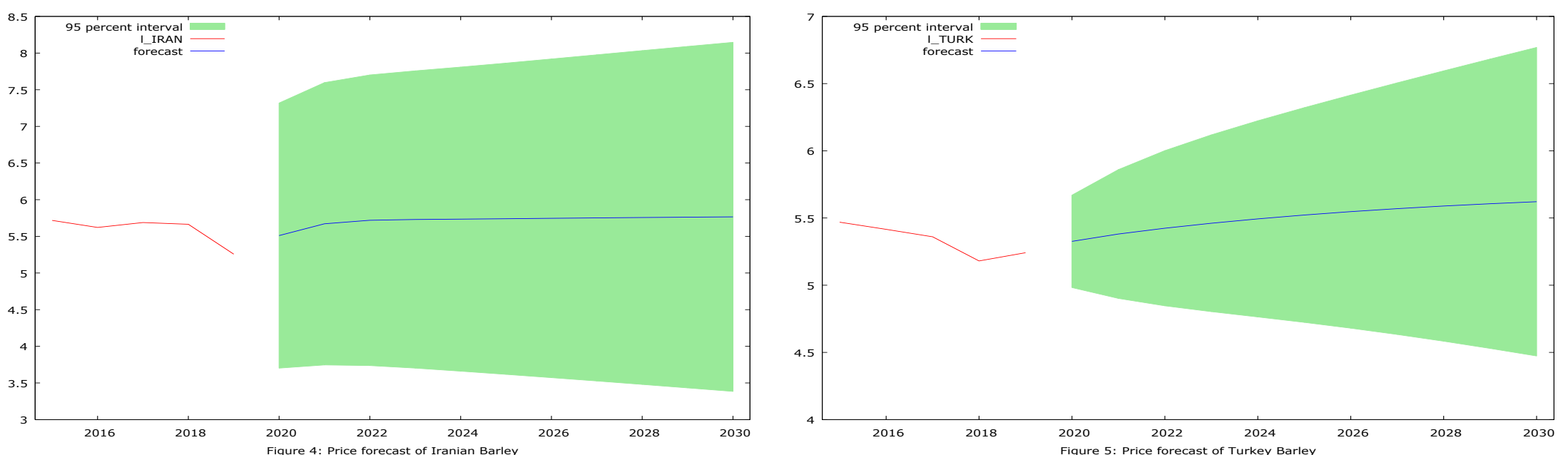

Figure 4: Price forecast of Iranian barley

Figure 5: Price forecast of Turkey barley 


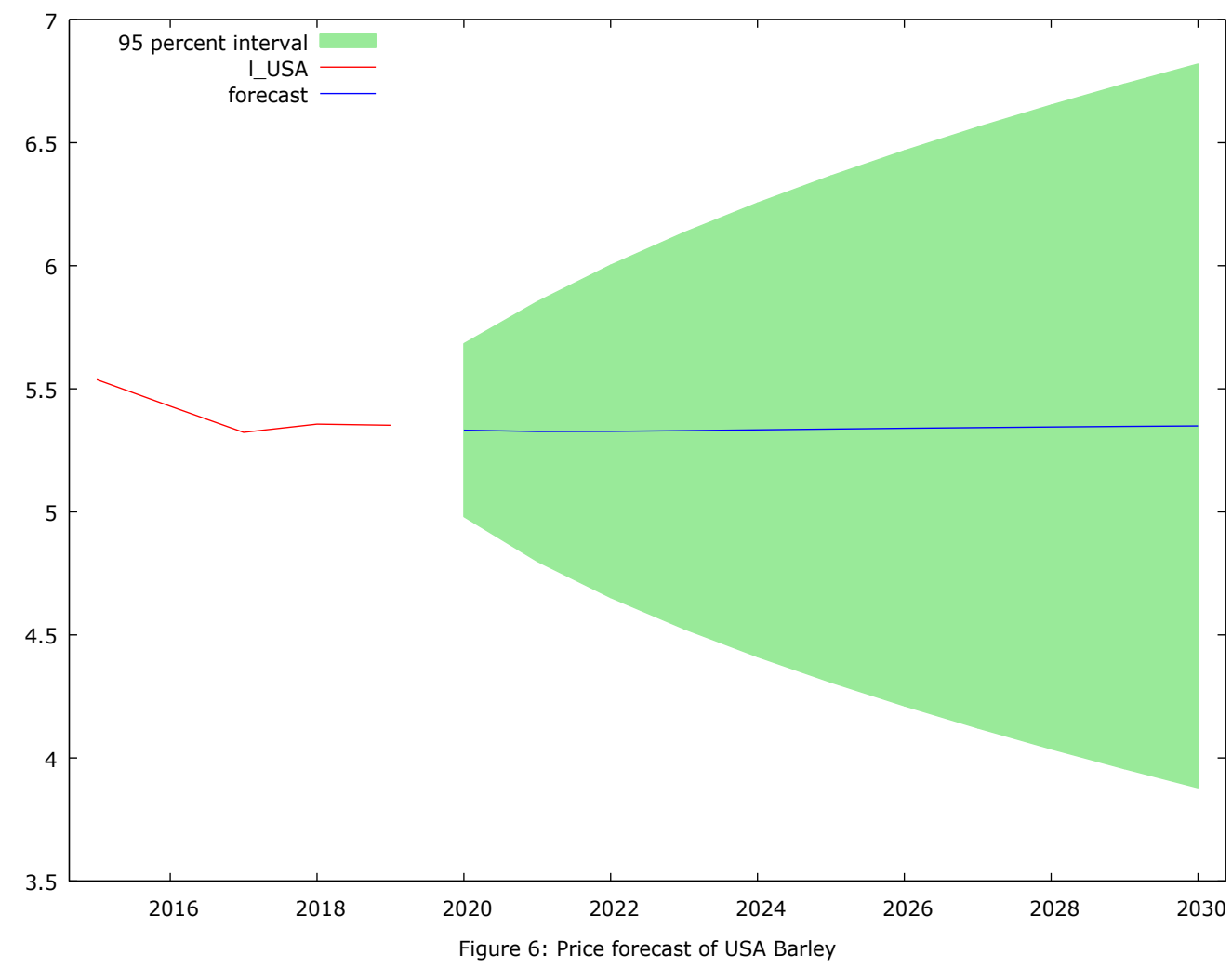

\section{CONCLUSION AND RECOMMENDATIONS}

Sequel to the findings it can be inferred that the law of one price holds among the market- there is a strong market integration among the markets as prices are perfectly transmitted vis-à-vis bivariate and multivariate integrations. However, only two markets viz. Australia and Canada were efficient as their degree of price integration were stable in the long run, thus capable of stabilizing the equilibrium in case of any shock-bad or good news that emanates from the shortrun dynamics. Furthermore, it was established that international boundary has little influence in segmenting the market pair of Canada and the USA. However, Australian and Iranian markets are large consumer markets. Besides, Canadian, USA and Turkey markets were found to be the import and export hubs of barley in the globe. Canadian and USA markets are the major markets that play a significant role in the barley market while the Australian market does not play a significant role in the trade. It was observed that the future prices of barley in the selected markets will be stable with a little inflationary effect that will owe to fluctuation in supply. Therefore, the research recommends the need to design a market network structure that will ensure price and allocative efficiencies across all the selected markets, thus making the prices of barley stable in the long run.

\section{REFERENCES}

Ahmed, M. and Singla, N.(2017).Market integration and price transmission in major onion markets of India. Economic Affairs, 62(3):405-417

Ardeni, P.G.(1989). Does the law of one price really hold for commodity prices? American Journal of Agricultural Economics, 71(3), 661

Barrett, C.B. and Li, J.(2002). Distinguishing between equilibrium and integration in spatial price analysis. American Journal of Agricultural Economics, 84:292-307.

Barrett, C.B.(2008).Spatial Market Integration. The New Palgrave Dictionary of Economics, Second Ed. London: Palgrave Macmillan.

Beag, F.A. and Singla, N.(2014).Cointegration, causality and impulse response analysis in major Apple markets of India. Agricultural Economics Research Review, 27(2):289-298.

Chengappa, P.G., Manjunatha, A.V., Vikas, D. and Khalil, S.(2012).Competitive assessment of onion markets in India. Institute for Social and Economic Change. Competition Commission of India, Pp. 1-86. 
Engle, R.F., and Granger, C.W.J.(1987).Cointegration and error correction: representation, estimation and testing. Econometrica, 55:251-276

Granger, C.W.J.(1969). Investigating causal relations by econometric models and cross-spectral methods. Econometrica: Journal of the Econometric Society, 37(1):424-438.

Johansen, S.(1988).Statistical analysis of cointegration vectors. Journal of Economic Dynamics and Control, 12(2-3):231-254

Larre, G.A.(2019). Market integration in the international market of soybeans: are GM soy and non-GM soy markets integrated? Journal of Agricultural Science, 11(15):14-22

Listorti, G. and Esposti, R.(2012).Horizontal price transmission in agricultural markets: Fundamental concepts and open empirical issues. Bio-based and Applied Economics, 1(1):81-108.

Mukhtar, T. and Javed, M.T.(2008).Market integration in wholesale maize markets in Pakistan. Regional and Sectoral Economic Studies, 8(2): 85-98.

Praveen, K.V. and Inbasekar, K.(2015).Integration of agricultural commodity markets in India. International Journal of Social Science, 4(1):51-56

Rahman, M.M. and Shahbaz, M.(2013).Do imports and foreign capital inflows lead economic growth? cointegration and causality analysis in Pakistan. South Asia Economic Journal, 14(1): 59-81.
Sadiq, M S., Singh, I.P., Aminu, S. and Grema, I. J. (2017).Volatility and price discovery of palm oil in international markets under different trade regime. Journal of Agricultural Economics, Environment and Social Sciences, 3(1): 33-50

Sadiq, M S., Singh, I.P., Suleiman, Aminu, Umar, S.M., Grema, I.J., Usman, B.I., Isah, M.A. and Lawal, A. T (2016).Extent, pattern and degree of integration among some selected cocoa markets in West Africa: An innovative information delivery system. Journal of Progressive Agriculture, 7(2): 22-39

Sadiq, M.S., Karunakaran, N. and Singh, I.P.(2018). Integration of banana markets in India. ICTACT Journal on Management Studies, 4(2):764-781

Sadiq, M.S., Singh, I.P. and Ahmad, M.M.(2020).Market integration of sesame seeds in South Asia. Alanya Academic Review, 4(1):143-155.

Sanogo, I. and Amadou, M.M.(2010). Rice market integration and food security in Nepal: The role of cross-border trade with India. Food Policy, 35: 312-322

Singh, N.(2014).A study of integration of markets for onion and potato in South Gujarat. International Research Journal of Agriculture Economics and Statistics, 5(2): 241-244.

Wani, M.H., Paul, R.K., Bazaz, N.H. and Manzoor, M.(2015).Market integration and price forecasting of apple in India. Indian Journal of Agricultural Economics, 70(2):171-181 